\title{
境界要素法による不規則波の港内静穆度解析 \\ Wave analysis in harbors for random waves with Boundary Element Method
}

工藤 康一" ${ }^{*}$. 浜中 建一郎 ${ }^{* *}$

Koichi Kudo, Ken-ichiro Hamanaka

There are several numerical method to analyze the wave field in harbors for random waves; finite difference method, finite element method and boundary element method, for example.

In the case where the constant depth can be assumed, the boundary element method is most useful. In the present paper, we establish the method to analyze the random wave field with the boundary element method. In particular, we establish the formulation of the method with the spectral representation of random waves.

Key words ; Random wave diffraction, Spectral representation, Boundary Element Method

\section{§1.はじめに}

不規則波に対する港内静稳度解析を数值解析で行う には、規則波に対する場合と同様に、差分法、有限要素 法、境界要素法があげられる。いずれの方法においても、 水深方向の流れの分布（あるいはポテンシャル形）を適 当に仮定することにより、平面 2 次元問題として解くこ とが出来る。これらの方法の一般的性質としては、差分 法は水深変化を取り入れることは容易であるが、直交格 子を基本とするため任意形状の港を扱うのは難しい。又、 有限要素法は水深変化と港の形状に関する扱いは容易 であるが、未知数の数と、それに伴う係数行列が大きく なり過ぎる。それに対し、境界要素法では、水深が一定 であるという制約はあるものの、任意形状の港の扱いは 容易であり、又、未知数も境界上にのみ配置すれぼよく、 有限要素法に比べ圧倒的に未知数が少なくてすむ。どの 方法が最も有利であるかは、解くべき問題によって異な るが、日本における多くの港では、航路を除き、ほぼ一 定水深に維持されていることを考慮すれば、境界要素法 が有利といえよう。

このことから本研究では、多方向性不規則波を入射波 とする港内静榣度解析を境界要素法によって行う場合 の解析方法の確立を目的とする。特に不規則波のスペク トル表現を用いた定式化を行う。

\section{§2. 不規則波動場の基碳方程式}

以下の、三つの仮定をする。

(1). 水媣一定の平面波動場。

(2). 線形解。

(3). 非圧縮性流体・非粘性流体の非回転運動。
速度ポテンシャルを $\Phi$ 、水面変動を $\eta$ とすると、基礎方 程式と境界条件は以下のようになる。

$$
\begin{aligned}
& \frac{\partial^{2} \Phi}{\partial x^{2}}+\frac{\partial^{2} \Phi}{\partial y^{2}}+\frac{\partial^{2} \Phi}{\partial z^{2}}=0 \\
& \left\{\begin{array}{l}
\Phi_{z}=\eta_{t} \text { on } z=0 \\
\Phi_{t}+g \eta=0 \text { on } \quad z=0 \\
\Phi_{z}=0 \text { on } z=-h
\end{array}\right.
\end{aligned}
$$

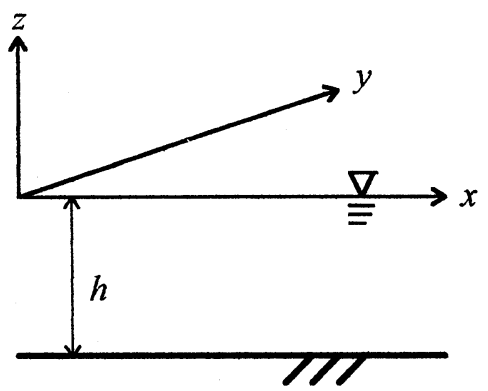

図.2

さらに、(2.2)式と(2.3)式から $\eta$ を消去すると、次式のよ うになる。

$$
\Phi_{z}+\frac{1}{g} \Phi_{t t}=0 \quad \text { on } \quad z=0
$$

具体的な問題に対しては、これに防波堤等の周囲の境界 条件が加わる。

\section{§3. 港内・港外の波動場について}

沖合いで発生した風波が構造物や島等により遮蔽さ れることなく、港口近傍に伝播したと考えると、港外の 波動場は進行波の重㸚合わせとしてのスペクトル表現 で記述出来る。

\footnotetext{
* 学生員 北海道東海大学大学院

** 正 員 北海道東海大学工学部海洋開発工学科
} 


$$
\begin{gathered}
\Phi=-i g \int \frac{\phi(\mathbf{k}, \omega)}{\omega} \frac{\cosh k(z+h)}{\cosh k h} e^{i(\mathbf{k} \cdot \mathbf{x}-\omega \cdot t)} d \mathbf{k} \cdot d \omega \\
\eta=\int \phi(\mathbf{k}, \omega) e^{i(\mathbf{k} \cdot \mathbf{x}-\omega \cdot t)} d \mathbf{k} \cdot d \omega
\end{gathered}
$$

これは、波向きに直角で直線の波峰線を持つ進行波を成 分とする表現である。又、 $\phi(\mathbf{k}, \omega)$ を確率振愊と呼ぶ。

一方、不規則な波動場は、水面変動のパワースペクトル

(方向スペクトル) で与えられることも多い。パワース ペクトルを $P(\mathbf{k}, \omega)$ とすると、確率振幅との関係は、次 のように表せる。

$$
P(\mathbf{k}, \omega)=\left\langle|\phi(\mathbf{k}, \omega)|^{2}\right\rangle
$$

ただし、ここで〈•〉は、アンサンブル平均を表す。波動 場の単位面積・単位時間当りの、全エネルギー $E$ は、次 のように表される。

$$
E=\int P(\mathbf{k}, \omega) d \mathbf{k} \cdot d \omega
$$

なおここで、k

次に、港内の波動場を考える。港口から入射した各々 の成分波は、一般的には回折波となって港内に進入し、 岸壁やその他の境界で反射し、回折波達の多重反射波動 場を形成する。従って、港内ではもはや波向きという概 念は成立せず、(3.1),(3.2)式に対応するスペクトル表現は 次のようになる。

$$
\begin{aligned}
& \Phi=-i g \int \frac{\phi(\omega)}{\omega} \frac{\cosh k(z+h)}{\cosh k h} e^{-i \omega t} d \omega \\
& \eta=\int \phi(\omega) e^{-i \omega t} d \omega
\end{aligned}
$$

(3.5),(3.6)式では、波向きに関する情報は含まれず、周波 数成分だけの重ね合わせとして表現されているが、方向 性に関する情報が一切含まれていないわけではなく、流 速に関してはある特定の方向(例えば、 $x$ 方向・ $y$ 方向) について、次のように表される。

$$
\begin{aligned}
& u=\frac{\partial \Phi}{\partial x}=-i g \int \frac{1}{\omega} \frac{\partial \phi}{\partial x} \frac{\cosh k(z+h)}{\cosh k h} e^{-i \omega t} d \omega \\
& v=\frac{\partial \Phi}{\partial y}=-i g \int \frac{1}{\omega} \frac{\partial \phi}{\partial y} \frac{\cosh k(z+h)}{\cosh k} e^{-i \omega t} d \omega
\end{aligned}
$$

特に水面では、 $z=0$ とすることにより、次のように表 せる。

$$
\begin{aligned}
& u=-i g \int \frac{1}{\omega} \frac{\partial \phi}{\partial x} e^{-i \omega t} d \omega \\
& v=-i g \int \frac{1}{\omega} \frac{\partial \phi}{\partial y} e^{-i \omega t} d \omega
\end{aligned}
$$

従って、領域内の考えている地点での確率振幅 $\phi(\omega)$ と、 その微係数が定まれば、その地点での波動場は定まるこ とになる。

次に、確率振幅が定まるとは、どの様な事なのふを考 えてみる。港外の波動場を平均值零のガウス形確率過程 と仮定すると、入射波もガウス形確率過程となり、その 確率振幅は平均值零のガウス形確率変数となる。港内の
波動場の速度ポテンシャルは、線形解析をしているから、 入射波の成分波の速度ポテンシャルの線形結合で表せ る。従って、港内の速度ポテンシャルの確率振幅は入射 波の確率振幅の線形結合となり、やはり平均值零のガウ ス形確率変数となる。従って、以下の様なその分散すな わちパワースペクトルが定まれば、港内の波動場は定ま ったことになる。

$$
P(\omega)=\left\langle|\phi(\omega)|^{2}\right\rangle
$$

\section{§4. 確率振幅に対する基䂸方程式と離散化}

(3.5)式で与えられた速度ポテンシャルを、(2.1)式に代 入し、全ての $t$ で成立すると仮定すると、次式が得られ る。

$$
\frac{\partial^{2} \phi}{\partial x^{2}}+\frac{\partial^{2} \phi}{\partial y^{2}}+k^{2} \phi=0
$$

また、水面の境界条件(2.5)式に代入することにより線形 分散関係式が得られる。

$$
\omega^{2}=g k \tanh k h
$$

底面の境界条件は、自動的に満足する。(3.5)式あるいは (4.1)式の $\phi$ は確立振幅であるから、 $\omega$ 軸上の関数として は、通常関数ではない。しかしながら、ある $\omega$ を固定し て、一つの見本值として見れば、 $x, y$ 空間上の通常関数 であり、(4.1)式は通常関数に対する微分方程式 （Helmhortz 方程式）とみなすことが出来、防波堤等の 周囲の境界条件と共に解くことが出来る。

次に、(4.1)式を数值的に解くことを考える。この場合、 全ての $\omega$ に対して解を求めることは不可能であるため、 何らかの離散化が必要となる。 $\omega$ 軸を適当な微小区間 $\Delta \omega$ で離散化する。 $j$ 番目U)区間U中心を $\omega_{j}$ とし、(3.11) 式の雨辺をその区間で積分する。

$$
\begin{aligned}
\int_{\omega_{j}-\frac{\Delta \omega}{2}}^{\omega_{j}+\frac{\Delta \omega}{2}} P(\omega) d \omega & =\int_{\omega_{j}-\frac{\Delta \omega}{2}}^{\omega_{j}+\frac{\Delta \omega}{2}}\langle\phi(\omega) \mid\rangle^{2} d \omega \\
& \cong P\left(\omega_{j}\right) \Delta \omega \equiv P_{j}
\end{aligned}
$$

今、実部・虚部が互いに独立で、平均值零、分散が各々 $P_{j} / 2$ のガウス形確立変数を考える。それを $\phi_{j}$ とする。 その様な $\phi_{j}$ から、次式を構成する。

$$
\begin{aligned}
& \Phi=-i g \sum_{j} \frac{\phi_{j}}{\omega_{j}} \frac{\cosh k_{j}(z+h)}{\cosh k_{j} h} e^{-i \omega_{j} t} \\
& \eta=\sum_{j} \phi_{j} e^{-i \omega_{j} t}
\end{aligned}
$$

ただし、

$$
\omega_{j}^{2}=g k_{j} \tanh k_{j} h
$$

(4.4)式と(4.5)式は、 $\Delta \omega \rightarrow 0$ の極限で各々(3.5)式と(3.6) 式に近づく（浜中：1988）。その意味で(4.4)式と(4.5)式 は、(3.5)式と(3.6)式の離散近似となっている。 
(4.4)式をあらためて(2.1)式に代入すれば、次式のような 離散化された確率振幅に対する基礎方程式となる。

$$
\frac{\partial^{2} \phi_{j}}{\partial x^{2}}+\frac{\partial^{2} \phi_{j}}{\partial y^{2}}+k_{j}^{2} \phi_{j}=0
$$

\section{§5. 境界要素法と境界条件}

(4.7)式の $\phi_{j}$ は、確率振幅であるが、§4で述べた様に、 一つの見本值と見ると、 $(x, y)$ の通常関数である。従っ て、(4.7)式は、通常の境界要素法で解くことか出来る。 その時、周囲の境界、すなわち、反射境界、開境界、部 分反射境界、入射・吸収境界に対しては、浜中（1994） と同様に与えることが出来る。

次に、入射波の条件を考える。港外において入射波は (3.1)，(3.2)式で表される。その時、波数 $\mathbf{k}$ の絶対值は分 散関係(4.2)式により $\omega$ で決まるから、波数ベクトルをあ る基準の軸からの角度 $\theta$ で次のように表わす。

$$
\mathbf{k}=\left(k_{x}, k_{y}\right)=(k \cos \theta, k \sin \theta)
$$

従って、(3.3)式は、次のように書き直す事が出来乃。

$$
P(\theta, \omega)=\left\langle|\phi(\theta, \omega)|^{2}\right\rangle
$$

(5.2)式を用いて、(4.4)(4.5)式と同様、(3.1)，(3.2)式を離 散化する。この場合は、 $\omega$ 軸だけでなく、 $\theta$ 軸も雁散化 し、以下のように表わす。

$$
\begin{aligned}
\int_{\theta_{i}-\frac{\Delta \theta}{2}}^{\theta_{i}+\frac{\Delta \theta}{2}} \int_{\omega_{j}-\frac{\Delta \omega}{2}}^{\omega_{j}+\frac{\Delta \omega}{2}}\left\langle|\phi(\theta, \omega)|^{2}\right\rangle d \theta d \omega \\
\quad=\int_{\theta_{i}-\frac{\Delta \theta}{2}}^{\theta_{i}+\frac{\Delta \theta}{2}} \int_{\omega_{j}-\frac{\Delta \omega}{2}}^{\omega_{j}+\frac{\Delta \omega}{2}} P(\theta, \omega) d \theta d \omega \\
\quad \cong P\left(\theta_{i}, \omega_{i}\right) \Delta \theta \Delta \omega=P_{i j}
\end{aligned}
$$

実部・虚部が互いに独立で、平均值零、分散が $\frac{P_{i j}}{2}$ のガ ウス形複素確率変数 $\phi_{i j}$ を考え、次式を構成する。

$$
\begin{aligned}
& \Phi=-i g \sum_{i} \sum_{j} \frac{\phi_{i j}}{\omega_{j}} \frac{\cosh k_{j}(z+h)}{\cosh k_{j} h} e^{i\left(\mathbf{k}_{i} \mathbf{x}-\omega_{j} t\right)} \\
& \eta=\sum_{i} \sum_{j} \phi_{i j} e^{i\left(\mathbf{k}_{i} \mathbf{x}-\omega_{j} t\right)}
\end{aligned}
$$

(4.4),(4.5)式の場合と同様に、(5.4),(5.5)式は、(3.1),(3.2) 式の離散近似となる。

境界要素法では、入射境界上で入射波の速度ポテンシ ヤル $\phi_{I}$ とその法線微分 $\frac{\phi_{I}}{v}$ が与えられなければならない から、(4.7)式の $\phi_{j}$ に対しては、(5.4)式より、次のように なる。

$$
\begin{aligned}
& \phi_{I}=-i g \sum_{i} \frac{\phi_{i j}}{\omega_{j}} e^{i \cdot \mathbf{k}_{i} \mathbf{x}} \\
& \frac{\phi_{I}}{v}=\left(v_{x}, v_{y}\right)\left(\frac{\partial \phi_{I}}{\partial x}, \frac{\partial \phi_{I}}{\partial y}\right) \\
& \text { ただし、 }
\end{aligned}
$$

$$
\begin{aligned}
& \frac{\partial \phi_{I}}{\partial x}=g \sum_{i} \frac{k_{x i}}{\omega_{j}} \phi_{i j} e^{i \cdot \mathbf{k x}} \\
& \frac{\partial \phi_{I}}{\partial y}=g \sum_{i} \frac{k_{y i}}{\omega_{j}} \phi_{i j} e^{i \cdot \mathbf{k x}}
\end{aligned}
$$

この $\phi_{i j}$ は、(4.4)(4.5)式の $\phi_{j}$ と同様に確率振幅であるが、 各々の $\phi_{i j}(i=1,2, \cdot)$ の見本值の一つの組に対して、不規 則入射波の一つの見本值 $\left(\phi_{I}, \frac{\partial \phi_{I}}{\partial v}\right)$ が定まり、それを入射 条件として解くことにより領域内の $\phi_{j}$ の見本值が一つ 定まる。

又、境界要素法では、始めに境界上のポテンシャルと その法線微分が求まり、それをもとの積分方程式に代入 することにより、領域内のポテンシャルが求められるが、 (3.7),(3.8)式の $\partial \phi / \partial x$ や $\partial \phi / \partial y$ を求めるには、積分方程式 を所定の方向で微分した Doublet 形の特異関数を用いた 積分方程式により求められる。

\section{§6. 領域内のパワースペクトル}

§5では、不規則入射波の一つの見本値に対して、領 域の速度ポテンシャル $\phi_{j}$ の一つの見本值が定まること を示した。一方§ 3 では、領域内の波動場が定まるとい うことは、 $\phi_{j}$ の分散、すなわち、パワースペクトルを定

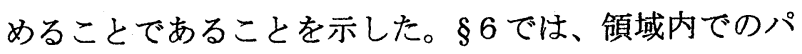
ワースペクトルを定める方法として三つの方法を提案 する。

\section{1. 個別法}

(5.4)式の様に、周波数を入射角で離散化した入射波の 各々の成分に対し、個別に解析し、最後に入射波のパワ 一スペクトルと確率振幅の独立性とから、領域内のパワ 一スペクトルを求める方法である。

$\left(\theta_{i}, \omega_{j}\right)$ の入射波の振幅を単位の $1\left(\phi_{i j}=1\right)$ として、

$$
\phi_{I}=-i \frac{g}{\omega_{j}} e^{i \cdot \mathbf{k}_{i} \cdot \mathbf{x}}
$$

とする。(6.1)式に対して、解いた領域内のある場所のポ テンシャルが、 $C_{i j}$ だったと仮定すると、 $\phi_{i j}$ に対しては、

(6.2)式となる。

$$
C_{i j} \phi_{i j}
$$

全ての入射角の成分を重わ合わせた入射波に対しては、 次のようになる。

$$
\phi_{j}=\sum_{i} C_{i j} \phi_{i j}
$$




$$
P\left(\omega_{j}\right)=\frac{\left\langle\left|\phi_{j}\right|^{2}\right\rangle}{\Delta \omega}=\sum_{j} C_{i j}{ }^{2} \frac{\left\langle\left|\phi_{i j}\right|^{2}\right\rangle}{\Delta \omega}=\sum_{j} \frac{C_{i j}{ }^{2} P_{i j}}{\Delta \omega}
$$

従って、一度係数 $C_{i j}$ を求めておけば、入射波の任意の パワースペクトルに対して、(6.4)式から領域内のパワー スペクトルが求められる。

\section{2. 周波数別法}

入射波の周波数 $\left(\omega_{j}\right)$ を固定して、その周波数のもと での全ての入射角を同時に考える。 $\phi_{i j}$ の実部・虚部の分 散が、 $\frac{P_{i j}}{2}$ であることを考虑して正規乱数によって $\phi_{i j}(i=1,2 ， \cdots)$ の見本值を一組定める。(5.6)(5.7)式から 入射波を求め、その入射波に対して解析を行い、領域内 の $\phi_{j}$ を求める。

上記の試行と解析を多数回繰り返すことにより、 $\phi_{j}$ の 多くの見本值を求め、その分散からパワースペクトルを 求める。

$$
P\left(\omega_{j}\right)=\frac{\left\langle\left|\phi_{j}\right|^{2}\right\rangle}{\Delta \omega}
$$

\section{3. 移動平均法}

周波数別法で行った一回の試行と解析を、周波数を微 小量づつ変えながら行い、得られた結果から移動平均に よりパワースペクトルを求める。

$$
P\left(\omega_{j}\right)=\frac{1}{\Delta \omega} \sum_{m=-M}^{M} W_{m}\left|\phi_{j+m}\right|^{2}
$$

ただし、

$$
\sum_{m=-M}^{M} W_{m}=1
$$

\section{§7. 各解法の特徴と考察}

個別法では、領域内のある一点について、係数行列 $C_{i j}(i=1,2, \cdots, j=1,2, \cdots)$ を予め求めて保存して おく必要がある。従って、垻域内の多数点でパワースへ クトルを求める必要がある時は多数の係数行列を保存 しておく必要がある。しかしながら、入射波のパワース ペクトル $P(\theta, \omega)$ が滑らかな関数と仮定される場合は、

$\theta$ と $\omega$ 軸の離散化は比較的粗くすることが出来る。その 場合、一地点の係数行列 $C_{i j}$ は比較的小さな行列で済む。

入射波のパワースペクトルを種々変えて、解析を行う必 要がある場合は、この方法が有利である。
周波数別法では、得られる領域内のパワースペクトル の有意性を獲得する為には、一つの $\omega_{j}$ に対し多数回の 試行と解析を行う必要がある。しかしながら、上で述べ たような入射波のパワースペクトルの滑らかさを仮定 できる場合は、 $\omega_{j}$ の離散化は比較的粗くすることが出 来る。この方法では、入射波の一つのパワースペクトル に対して、領域内の広い範囲でパワースペクトルを求め る必要がある場合に有利である。

移動平均法では、一つの $\omega_{j}$ に対する試行と解析は一 回で良いが、得られる領域内のパワースペクトルの有意 性を獲得するためには、 $\omega_{j}$ の離散化は密に行う必要が ある。すなわち、周波数別法と同程度の精度を得る為に は、周波数別法と同程度の回数の試行と解析を行う必要 があり、両方法は本質的には同じである。従って、この 方法の有利さは周波数別法と同じである。

周波数別法と移動平均法では、入射波の確率振幅の一 組の見本值に対し解析し、領域内のポテンシャルの見本 值を得る。これを繰り返して多くの見本值から分散を求 めるという意味で、両解析法は、本質的に同じである。 この場合、入射波の確率振幅は、計算機によって発生さ せた乱数を用いることになる。試行と解析は有限回しか 行えないから、領域内のポテンシャルの分散は、有限個 の見本值からの推定によるものになる。統計的な有意性 を得るために、どの程度の回数の試行と解析が必要とな るかは、解析が線形解析であることを考えると、最終的 には計算機が発生させる乱数の特性によるだろう。図. 7 は、この事を述べた一例である。計算機によって発生 させた平均值零、分散 1 の正規乱数の見本值の 2 乗平均 から推定した分散で、横軸は見本值の個数を表している。 各々の図の各々の曲線は初期值を異にしている。なお正 規乱数は $(0,1)$ 区間の一様乱数の 12 個の見本值から中 心極限定理により構成したものである。

これ等の図によれば、図.7-(b)の様に100 個程度で、 ほぼ目標の分散 1 になる場合もあるが、初期値が異なれ ば、図.7-(f)の様に、なかなか収束しない場合もある。 全体的には、1 割程度の誤差を認めても、数 100 回の試 行が必要となる。これは実際の解析作業を考えれば、現 実的とは言えない。

勿論、ここで用いた正規乱数の構成法と異なる構成法 を用いれば、異なった結果が得られるであろうが、周波 数別法や移動平均法を用いる場合は、予め用いる正規乱 数の特性を充分吟味しておく必要があるだろう。 
(a)

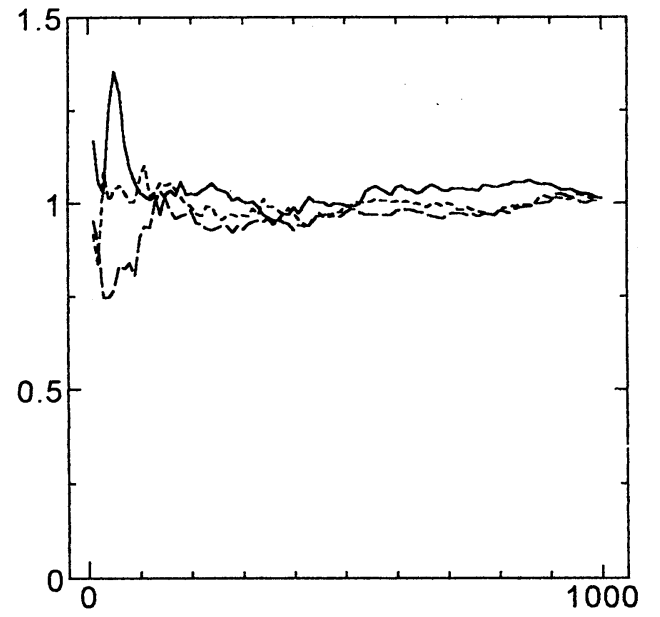

(b)

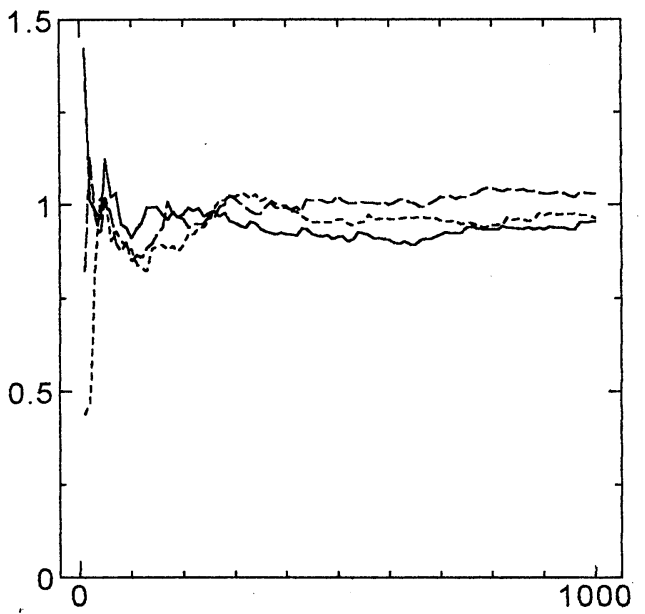

(c)

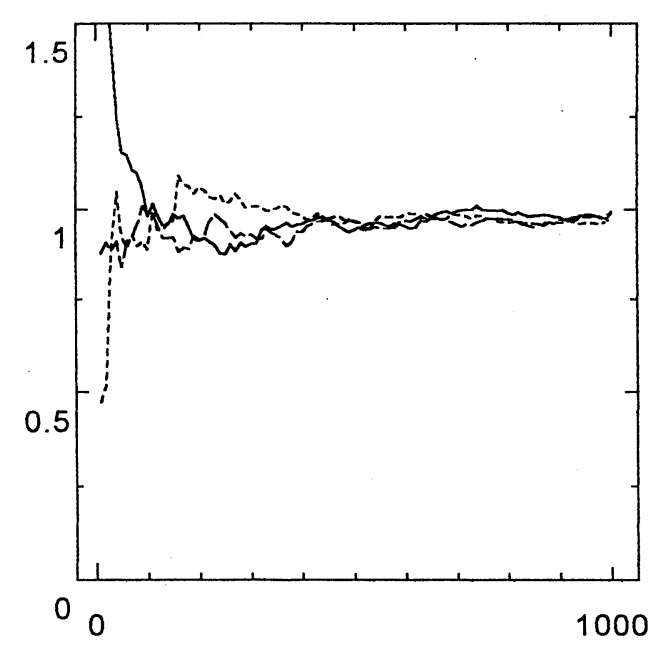

(d)

（初期値 $=13 ）$

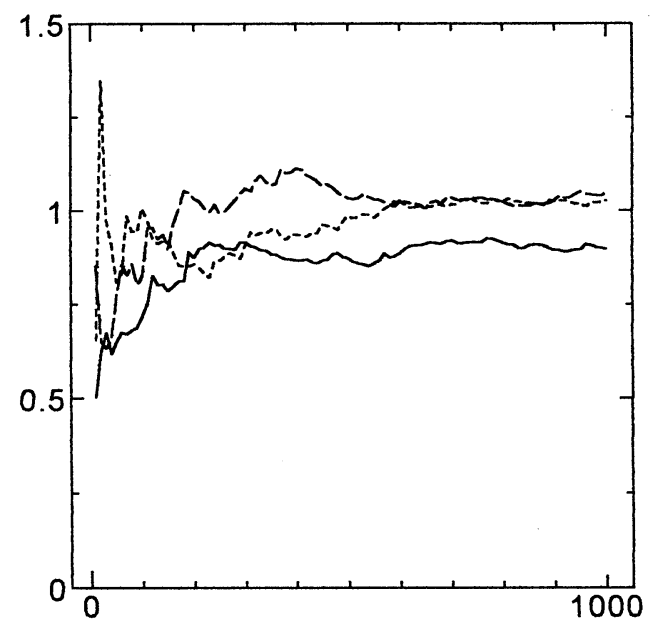

(e)

（初期値 $=33$ ）

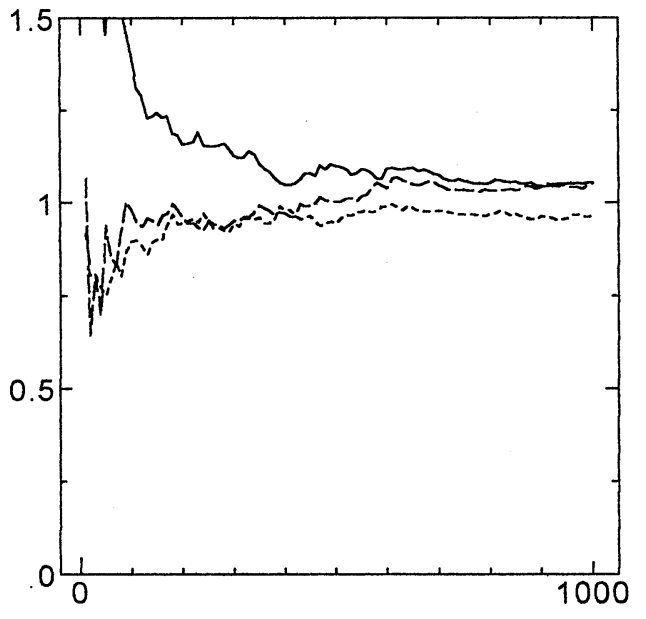

(f)

（初期值 $=50$ )

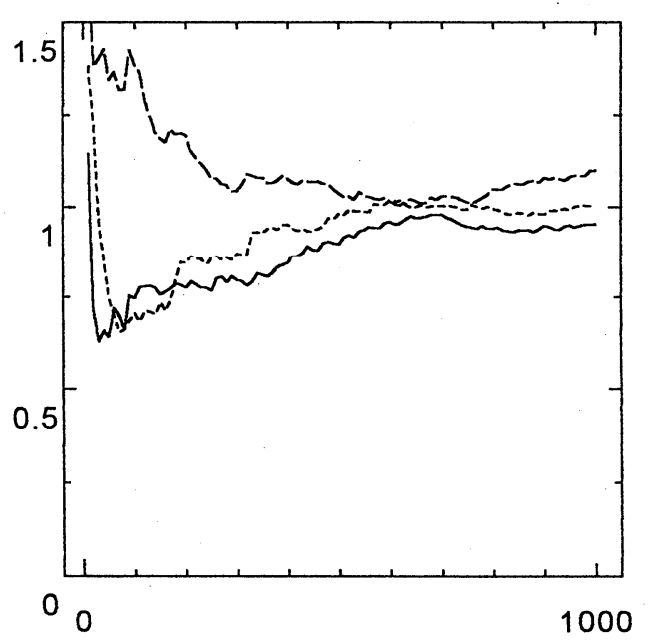

図. 7

\section{参考文献}

濱中建一郎（1988）：スペクトル解析と不規則波の浅水変形，水工学シリーズ，88-B-7, pp.B-7-1〜B-7-17 濱中建一郎（1995）：グリーンの公式を用いた静穏度解析における種々の境界条件について，海岸工学論文集， 第 42 巻 (2), pp. $996 \sim 1000$ 